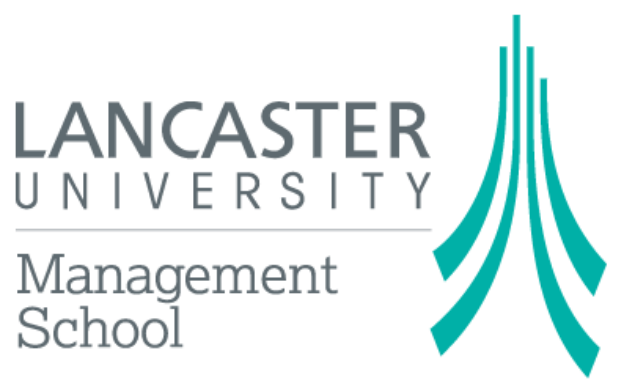

Economics Working Paper Series

2014/012

\title{
Limited Asset Market Participation, Income Inequality and Macroeconomic Volatility
}

Giorgio Motta and Patrizio Tirelli

The Department of Economics

Lancaster University Management School

Lancaster LA1 4YX

UK

All rights reserved. Short sections of text, not to exceed two paragraphs, may be quoted without explicit permission, provided that full acknowledgement is given. 


\title{
Limited Asset Market Participation, Income Inequality and Macroeconomic Volatility.
}

\author{
Giorgio Motta* \\ University of Lancaster
}

\author{
Patrizio Tirelli ${ }^{\dagger}$ \\ University of Milano Bicocca
}

May 2014

\begin{abstract}
By introducing external consumption habits and Limited Asset Market Participation in an otherwise standard New Keynesian DSGE model we uncover a causality link between limited asset market participation, consumption inequality and macroeconomic volatility. We also obtain that monetary contractions have redistributive effects in favour of asset holders, broadly confirming the findings in Coibion et al. (2012). Finally we analyze the impact of redistributive fiscal policies that target consumption inequality between households groups. Such policies have beneficial implications for macroeconomic stability, bringing the dynamic performance of the model close to the one generated by representative-agent DSGE models.
\end{abstract}

JEL codes: E52, E63

Keywords: Limited Asset Market Participation, DSGE, Determinacy, Consumption Habits, Income Inequality, Redistribution.

\footnotetext{
*Corresponding author: Department of Economics, Lancaster University Management School, LA1 4XY, United Kingdom. E-mail: g.motta@lancaster.ac.uk

${ }^{\dagger}$ Patrizio Tirelli gratefully acknowledges financial support from EC project 320278- RASTANEWS.
} 


\section{Introduction}

The years following the global 2007 financial crisis have witnessed growing concern for incomes inequality and for the distributional effects of macroeconomic policies. Historically, redistributive actions have been the domain of fiscal policies, but in recent years even monetary policies have come under scrutiny for their effects on inequality. For instance Coibion et al. (2012) document that in the US monetary policy contractions have substantial and persistent redistributive effects, increasing income and consumption inequality. In this paper we investigate the link between inequality, macroeconomic volatility and monetary policy in a dynamic stochastic general equilibrium (DSGE) model.

Theoretical and empirical dynamic DSGE models used for monetary policy analysis, such as Smets and Wouters (2007), are ill-suited to address this issue, due to pervasiveness of the representative agent hypothesis. Recent developments do introduce a distinction between entrepreneurs and the rest of the households in the economy (Christiano et al. 2010; Brave, Campbell, Fisher, and Justiniano, 2012; Del Negro Giannoni and Schorfheide, 2013), but the characterization of entrepreneurs' function in the model is tailored to generate a financial accelerator and cannot generate redistributive effects for monetary policy shocks.

Following Mankiw (2000), we base our analysis on the Limited Asset Market Participation hypothesis (LAMP henceforth), drawing a distinction between agents who have full access to financial markets (Ricardian agents henceforth) and agents who do not participate in financial markets (RT consumers henceforth). Indirect support for the LAMP hypothesis is found in recent studies that document households responses to temporary tax-reductions and public transfers increases (Johnson et al., 2006; Shapiro and Slemrod, 2009; Parker et al. 2011). Iacoviello and Pavan (2013) point out that $40 \%$ of US households hold no wealth and no debt. Similar figures obtain on average in the Euro area (Cowell, Karagiannaki and McKnight, 2012). Anderson, Inoue and Rossi (2013) use US microdata to estimate individual-level impulse responses as well as multipliers for government spending and tax policy shocks. They find that wealthiest individuals tend to behave according to the predictions of standard DSGE models, whereas the poorest individuals tend to behave like RT consumers. Indeed the fiscal stimuli implemented in response to the 2007-08 financial crisis (Oh and Reis, 2011) were largely based on increased public transfers, apparently meant to support consumption of liquidity-constrained households.

Bringing LAMP into an otherwise standard DSGE model allows to obtain a steady state characterize by inequality in wealth holdings. This seems broadly consistent with empirical evidence on wealth distribution in the US and in a number of developed economies, where half of all households hold more than $90 \%$ of net wealth (Cowell, Karagiannaki, and McKnight, 2012).

The Lamp hypothesis has characterized a rapidly expanding literature which investigates the dynamic stability of DSGE models where RT consumers cannot smooth consumption over the business cycle. Galì et al. (2004) and Bilbiie (2008, Bilbiie henceforth) showed that satisfying the Taylor principle may not ensure model determinacy in a very simple model where price stickiness and LAMP are the only frictions. This result obtains because imperfect price adjustment to wage increases causes profit losses which are entirely borne by Ricardian agents. As a consequence, a real interest rate increase may be associated to a surge in aggregate demand and production even if it induces a fall in the consumption of Ricardian agents. In contrast with Bilbiie, Ascari et al. (2011) show that a modest amount of nominal wage rigidity is sufficient to limit profit volatility and to restore the standard Taylor Principle even for a very large share of RT consumers. Other contributions show that internal consumption habits (Motta and Tirelli, 2012) and steady state 
income and consumption inequality between the two consumer groups (Natvik, 2012)) restore the Bilbiie result for empirically plausible calibrations of a business cycle model characterized by price and nominal wage rigidities.

Our model differs from previous contributions to the LAMP literature in three key aspects. First, we assume external consumption habits, in the catching-up-with-the-Joneses tradition popularized by Abel (1990) and widely used thereafter (Smets and Wouters, 2007; Christoffel, Coenen and Warne, 2008). This allows to model the reaction of wage setting decisions to RT households' concern for relative consumption levels, a key driver for our results. Note that recent works do account for external habits and LAMP, but the wage sensitivity to RT concern for relative consumption is removed through some ad hoc assumptions (Coenen and Straub, 2005), Forni, Monteforte Sessa, 2009; Coenen, Straub and Trabandt, 2012; Furlanetto and Seneca, 2012). Second, we extend the basic labor-only production function to include capital accumulation. This, in turn, allows to investigate the effects of wealth holdings inequality on dynamic stability and on the dynamic adjustment to monetary policy shocks. Third, we analyze the impact of redistributive fiscal policies that target consumption inequality between the two households groups.

In a nutshell, our key results are summarized as follows. External habits and consumption inequality have mutually reinforcing adverse effects on determinacy. This implies that model features which raise consumption inequality, i.e. net returns on physical capital and monopoly profits in the goods market equilibrium, lower the threshold share of RT consumers which triggers indeterminacy. Fiscal transfer policies that reduce steady state consumption inequality have a strongly beneficial effect on dynamic stability, drastically increasing the threshold share of RT consumers that triggers indeterminacy. In contrast with previous results obtained in LAMP models based on the internal habits hypothesis (Motta and Tirelli 2012), no beneficial effect can be obtained from purely countercyclical fiscal transfers that cannot affect long run income distribution. To the best of our knowledge this is the first contribution that identifies a link between long-run inequality and macroeconomic instability in a New-Keynesian DSGE model.

Turning to the analysis of monetary policy shocks we are able to document that unexpected monetary contractions do have a persistent negative effect on income distribution and consumption inequality: monetary contractions are in fact associated to a fall in labor incomes. Activation of steady state fiscal transfer policies substantially dampens the redistributive effects of monetary policies and brings the dynamic performance close to the predictions of DSGE models based on the representative agent hypothesis. Both common wisdom and recent empirical work (Immervoll and Richardson, 2011) suggest that governments implement a substantial amount of income redistribution through their tax/benefits systems. We provide an additional theoretical argument supporting such policies.

Our concern for the redistributive effects of shocks and monetary policies in the context of DSGE models is shared by Monacelli et al. (2011) who distinguish between bond holders and entrepreneurs who also are stock holders. The latter are relatively impatient and obtain loans from bond holders subject to a borrowing constraint determined by their capital holdings. We emphasize two key differences between our results and theirs. First, in their framework a contractionary interest rate shock leaves stock holders worse off relative to workers, who are also the bond holders. Second, in spite of financial frictions, a substantial amount of risk sharing occurs between the two groups, and the effect of shocks on the economy is dampened relative to our model.

The rest of the paper is organized as follows. In the next section we describe in detail the model structure, then in section 3 we present the results concerning the model stability. Section 4 presents the model's dynamic response to a monetary shock. Section 5 concludes. 


\section{The Model}

In this section we lay out the structure of the model without capital in the firms production function. Ricardian households participate in financial markets, base their choices on intertemporal optimization and react to real interest rate changes. By contrast, RT consumers do not hold any wealth. For expositional purposes we consider first a model where production requires no capital, so that income inequality is only due to firms monopoly profits.

\subsection{Households preferences}

Households are indexed by $i$, where $i \in[0,1]$. RT $(r t)$ and Ricardian $(o)$ consumers are defined over the intervals $[0, \theta]$ and $(\theta, 1]$ respectively. The common preferences are characterized by the following utility function:

$$
U_{t}^{i}=E_{0} \sum_{t=o}^{\infty} \beta^{t}\left[\ln \left(c_{t}^{i}-b c_{t-1}\right)-\frac{\psi_{l}}{1+\phi_{l}}\left(h_{t}^{i}\right)^{1+\phi_{l}}\right]
$$

where $c^{i}=\left[\int_{0}^{1}\left(c^{i}(z)\right)^{\frac{\eta-1}{\eta}} d z\right]^{\frac{\eta}{\eta-1}}$ represents individual consumption of a basket of differentiated goods, $b$ denotes external habits as in Smets and Wouters $(2003,2005,2007), c=\int_{0}^{1} c^{i} d i$ is aggregate consumption and $h_{t}^{i}=\left\{\int_{0}^{1}\left[h_{t}^{i}(j)\right]^{\frac{\alpha_{w}-1}{\alpha_{w}}} d j\right\}^{\frac{\alpha_{w}}{\alpha_{w}-1}}$ denotes individual supply of a differentiated labour bundle.

\section{$2.2 \quad$ Firms}

Goods markets are monopolistically competitive, and good $z$ is produced with the following technology:

$$
y_{t}(z)=h_{t}(z)
$$

where $h_{t}(z)$ is the composite labor input used by each firm $z$. Firms $z$ demand for labor type $j$ is

$$
h_{t}^{j}(z)=\left(\frac{W_{t}^{j}}{W_{t}}\right)^{-\alpha_{w}} h_{t}^{d}(z)
$$

where $W_{t}=\left[\int_{0}^{1}\left(W_{t}^{j}\right)^{1-\alpha_{w}} d j\right]^{1 /\left(1-\alpha_{w}\right)}$ defines the wage index.

The real marginal costs is:

$$
m c_{t}=w_{t}(1-\rho)
$$

where $w_{t}=\frac{W_{t}}{P_{t}}$ is the real wage rate and $\rho$ is a fiscal subsidy which is financed by levying a lump-sum $\operatorname{tax}, T^{L S}$, on firms. 


\subsubsection{Sticky Prices}

Price stickiness is based on the Calvo mechanism. In each period a fraction $\left(1-\lambda_{p}\right)$ of firms reoptimize and set the price $\widetilde{P}_{t}$ that maximizes the discounted sum of expected future profits: ${ }^{1}$

$$
E_{t} \sum_{s=0}^{\infty}\left(\beta \lambda_{p}\right)^{s} \lambda_{t+s}\left(\widetilde{P}_{t}-P_{t+s} m c_{t+s}\right) y_{t+s}(z)
$$

subject to:

$$
y_{t+s}(z)=y_{t+s}^{d}\left(\frac{\widetilde{P}_{t}}{P_{t+s}}\right)^{-\eta}
$$

where $y_{t}^{d}$ is aggregate demand and $\lambda_{t}$ is the stochastic discount factor.

The first order condition (FOC) for this problem is

$$
E_{t} \sum_{s=0}^{\infty}\left(\beta \lambda_{p}\right)^{s} \lambda_{t+s} y_{t+s}^{d}\left[\begin{array}{c}
(1-\eta) \widetilde{P}_{t}^{-\eta}\left(P_{t+s}\right)^{\eta}+ \\
+\eta \widetilde{P}_{t}^{-\eta-1} P_{t+s}^{\eta+1} m c_{t+s}
\end{array}\right]=0
$$

\subsection{Ricardian Households}

Ricardian households maximize (1) subject to the following period budget constraint.

$$
B_{t+1}+P_{t} c_{t}^{o}=P_{t} d_{t}+R_{t-1} B_{t}+h_{t}^{d} \int_{0}^{1} W_{t}^{j}\left(\frac{W_{t}^{j}}{W_{t}}\right)^{-\alpha_{w}} d j
$$

Where $B$ defines nominally riskless bond, $R$ is the nominal interest rate and $d$ defines real dividends.

The Euler equation is

$$
\lambda_{t}^{o}=\beta E_{t} \lambda_{t+1}^{o} \frac{R_{t}}{\pi_{t+1}}
$$

where

$$
\lambda_{t}^{o}=\frac{1}{c_{t}^{o}-b c_{t-1}}
$$

defines consumption marginal utility.

\subsection{Rule-of-Thumb Households}

RT consumers are not able to either save or borrow and always consume their current income:

$$
P_{t} c_{t}^{r t}=W_{t} h_{t}^{r t}
$$

\footnotetext{
${ }^{1}$ These firms face symmetrical marginal costs.
} 


\subsection{Labor market}

For each labor input there is a union $j$ which monopolistically sets the nominal wage, $W_{t}^{j}$, subject to (3). Each household $i$ supplies all labour types at the given wage rates ${ }^{2}$ and the total number of hours allocated to the different labor markets must satisfy the time-resource constraint

$$
h_{t}^{i}=\int_{0}^{1} h_{t}^{j} d j=\int_{0}^{1}\left(\frac{W_{t}^{j}}{W_{t}}\right)^{-\alpha_{w}} h_{t}^{d} d j
$$

Ricardian and non-Ricardian households work for the same amount of time because we assume that the two groups are uniformly distributed across unions, and demand for each labour type is uniformly distributed across households, as in Galì et al. (2007). Individual labor income therefore is

$$
h_{t}^{d} W_{t}=\int_{0}^{1} W_{t}^{j}\left(\frac{W_{t}^{j}}{W_{t}}\right)^{-\alpha_{w}} h_{t}^{d} d j
$$

Finally, we assume that the representative union objective function is a weighted average $(1-\theta$, $\theta$ ) of the utility functions of the two households types (see Colciago, 2011; Motta and Tirelli, 2012). This, in turn, implies that with flexible wages

$$
w_{t}=\frac{W_{t}}{P_{t}}=\mu_{w} \frac{\psi_{l} h_{t}^{\phi_{l}}}{\left[(1-\theta) \lambda_{t}^{o}+\theta \lambda_{t}^{r t}\right]}
$$

where

$$
\lambda_{t}^{r t}=\frac{1}{c_{t}^{r t}-b c_{t-1}}
$$

is the RT marginal utility of consumption and $\mu^{w}=\frac{\alpha_{w}}{\left(\alpha_{w}-1\right)}$ represents the wage markup.

\subsection{Aggregation}

Aggregation yields:

$$
y_{t}=h_{t}=c_{t}
$$

where

$$
\begin{gathered}
c_{t}=\theta c_{t}^{r t}+(1-\theta) c_{t}^{o} \\
h_{t}=\int_{0}^{1} h_{t}^{i} d i
\end{gathered}
$$

\subsection{Monetary Policy}

Monetary policy follows a standard Taylor rule

$$
\frac{R_{t}}{R}=\left(\pi_{t}\right)^{\phi_{\pi}}
$$

\footnotetext{
${ }^{2}$ The assumption is that wages always remain above the marginal rate of substitution of all households. Therefore, households are willing to meet the labor demand of firms.
} 


\subsection{The model in log-linear form}

We take a log-linear approximation around the zero-inflation deterministic steady state ${ }^{3}$. Right from the outset note that dynamics are affected by the steady-state relative consumption shares of the two groups

$$
\begin{aligned}
\frac{c^{r t}}{c} & =\frac{1}{\mu(1-\rho)} \\
\frac{c^{o}}{c} & =\frac{1}{1-\theta}-\frac{\theta}{1-\theta} \frac{c^{r t}}{c}
\end{aligned}
$$

where $\mu=\frac{\eta}{\eta-1}$ defines the price markup.

\subsubsection{Supply side}

$$
\begin{gathered}
\hat{y}_{t}=\hat{h}_{t} \\
\hat{w}_{t}=\phi_{l} \hat{h}_{t}-\left[(1-\theta) \hat{\lambda}_{t}^{o}+\theta \hat{\lambda}_{t}^{r t}\right] \\
\hat{\lambda}_{t}^{j}=-\frac{1}{\left(\frac{c^{j}}{c}\right)-b}\left[\left(\frac{c^{j}}{c}\right) \hat{c}_{t}^{j}-b \hat{c}_{t-1}\right] ; j=o, r t \\
\widehat{m c}_{t}=\hat{w}_{t} \\
\hat{\pi}_{t}=\kappa\left(\frac{1}{1-b}+\phi_{l}\right) \hat{y}_{t}-\kappa\left(\frac{b}{1-b}\right) \hat{y}_{t-1}+\beta \hat{\pi}_{t+1} ; \\
\kappa=\frac{\left(1-\lambda_{p}\right)\left(1-\beta \lambda_{p}\right)}{\lambda_{p}}
\end{gathered}
$$

\subsubsection{Demand side}

$$
\begin{gathered}
\hat{c}_{t}^{r t}=\hat{w}_{t}+\hat{h}_{t} \\
\hat{\lambda}_{t}^{o}=E_{t} \hat{\lambda}_{t+1}^{o}+\hat{R}_{t}-E_{t} \hat{\pi}_{t+1} \\
\hat{y}_{t}=\hat{c}_{t}=(1-\theta) \frac{c^{o}}{c} \hat{c}_{t}^{o}+\theta \frac{c^{r t}}{c} \hat{c}_{t}^{r t}
\end{gathered}
$$

\subsubsection{Monetary policy rule}

$$
\hat{R}_{t}=\phi_{\pi} \hat{\pi}_{t} .
$$

\footnotetext{
${ }^{3}$ Hatted variables denote the log-deviation of a variable from its zero-inflation, deterministic steady-state value.
} 


\section{$3 \quad$ Stability analysis}

In this section we investigate the effects that habits and consumption inequality have on determinacy. To identify the role of habits we posit that the production subsidy $\rho=\rho^{*}$ brings production at the competitive level. Under the additional assumption that the subsidy is entirely financed by lump-sum taxes levied on firms, as in Ascari et al. (2011), this implies that in steady state firms profits are nil, and that consumption is identical for the two consumer groups. From (20), (21), (22) we get

$$
\hat{w}_{t}=\left(1+\phi_{l}+\frac{b}{1-b}\right) \hat{y}_{t}-\frac{b}{1-b} \hat{y}_{t-1}
$$

Note that due to price stickiness, firms profits are the inverse of marginal cost deviations from steady state. ${ }^{4}$

$$
\hat{d}_{t}=-\widehat{m c}_{t}=-\left(1+\phi_{l}+\frac{b}{1-b}\right) \hat{y}_{t}+\frac{b}{1-b} \hat{y}_{t-1}
$$

Using (20), (28), (30), and (31) it is easy to see that in equilibrium each optimizing household must consume $^{5}$

$$
\hat{c}_{t}^{o}=\hat{w}_{t}+\hat{h}_{t}+\frac{\hat{d}_{t}}{1-\theta}=\chi \hat{y}_{t}+\frac{\theta}{(1-\theta)} \frac{b}{1-b} \hat{y}_{t-1}
$$

where $\chi=\left[1-\frac{\theta}{(1-\theta)}\left(\phi_{l}+\frac{1}{1-b}\right)\right]$.

When $\theta=0$ (and $\chi=1$ ), an increase in current output is associated with a real wage increase and with a profits reduction that exactly offset each other. By contrast, when $\theta>0$ the increase in output entails a redistribution of income from asset holders to RT consumers captured by term $-\frac{\theta}{(1-\theta)}\left(\phi_{l}+\frac{1}{1-b}\right)$ in $\chi$. For "large" values of $\theta$, profit losses exceed the positive labor income variation determined by the increase in output. In this case $\chi<0$ and $\hat{c}_{t}^{o}$ is inversely related to $\hat{y}_{t}$. This point was initially raised by Billbie (2008), who demonstrated that the negative value of $\chi$ is associated to indeterminacy. Here we show that $\chi$ unambiguously falls in $b$. From (21) and $(22)$, it is easy to see that this happens because habits raise the sensitivity of $\hat{\lambda}_{t}^{j}$ to $\hat{c}_{t}^{j}$, inducing a stronger reaction of wages to output.

By substituting (32) into (27) we get the New Keynesian IS curve

$$
\hat{y}_{t}=\frac{A}{(A+B)} \hat{y}_{t-1}+\frac{B}{(A+B)} \hat{y}_{t+1}-\frac{\left(\hat{R}_{t}-\hat{\pi}_{t+1}\right)}{(A+B)}
$$

where $A=\frac{b}{1-b}\left(1-\frac{1}{1-b} \frac{\theta}{1-\theta}\right), B=\frac{1}{1-b} \chi$.

Note that $(A+B)=\frac{1}{1-b}\left[\left(b\left(1-\frac{1}{1-b} \frac{\theta}{1-\theta}\right)\right)+\chi\right]=\frac{1}{1-b}\left[1-\frac{\theta \phi_{l}}{(1-\theta)}+b-\frac{(1+b)}{1-b} \frac{\theta}{1-\theta}\right]<0$ causes the inversion of the IS curve. It is quite apparent that the habits coefficient has negative effect on $(A+B)$ if $\frac{(1-b) b}{(1+b)}<\frac{\theta}{1-\theta}$.

Proposition 1 Under a Taylor rule that controls contemporaneous inflation the model is stable and uniquely determined if $\theta$ does not exceed a threshold $\theta^{* *}$ such that $(A+B)>-\frac{\kappa\left(\left(\phi_{l}+\frac{1}{1-b}\right)+\frac{b}{1-b}\right)\left(\phi_{\pi}+1\right)}{2(\beta+1)}$,

\footnotetext{
${ }^{4}$ Due to the efficient steady state assumption, profits are defined here as a fraction of steady state output.

${ }^{5} \hat{d}_{t}$ is defined as a fraction of steady state output.
} 
that is

$$
\theta^{* *}=\frac{\left\{1+b+\frac{(1-b) \kappa\left[\left(\phi_{l}+\frac{1}{1-b}\right)+\frac{b}{1-b}\right]\left(\phi_{\pi}+1\right)}{2(\beta+1)}\right\}}{\left(\frac{1+b}{1-b}+\phi_{l}\right)+\left\{1+b+\frac{(1-b) \kappa\left[\left(\phi_{l}+\frac{1}{1-b}\right)+\frac{b}{1-b}\right]\left(\phi_{\pi}+1\right)}{2(\beta+1)}\right\}}
$$

Proof. See Appendix A

Further insights on determinacy require that we impose restrictions on parameters. The parameter governing the degree of habit persistence, $b$, and the labor utility parameter, $\phi_{l}$ are respectively set at 0.65 and 3, well in the ranges of the estimates obtained by Smets and Wouters (2005). We set $\beta=(1.03)^{-0.25}$ which implies a steady-state annualized real interest rate of about $3 \%$. Values for price stickiness are taken from Christiano et al. (2005), $\lambda_{p}=0.6$, who find that prices are optimized every 2.5 quarters. This, in turn, implies that $\kappa=0.2696$

Under our benchmark calibration we obtain that the inversion of (33) occurs at $\theta>\theta^{*} \simeq 0.18$, whereas $\theta^{* *} \simeq 0.21 .^{6}$ Larger consumption habits unambiguously lower the threshold value $\theta^{* *}$. In fact we obtain $\frac{\partial \theta^{* *}}{\partial b}<0$ for $0.2<\phi_{l}<100,0 \leq b<1,1<\phi_{\pi}<100$. The inverse of the Frish elasticity, $\phi_{l}$, typically lies in the range $0.2-5$ In Figure 1 we show that the corresponding value for $\theta^{* *}$ monotonically falls from 0.25 to 0.1

\subsection{The role of consumption inequality}

If we relax the zero steady-state profits assumption, i.e. $\rho=0$, we get $\frac{c^{r t}}{c}=\frac{1}{\mu}, \frac{c^{o}}{c}=\frac{1-\theta \frac{1}{\mu}}{1-\theta}$. Condition (32) now becomes ${ }^{8}$

$$
\hat{c}_{t}^{o}=\frac{1}{1+\frac{(\mu-1)}{1-\theta}} \chi^{*} \hat{y}_{t}+\frac{\frac{\mu}{1-\theta}-1}{1+\frac{(\mu-1)}{1-\theta}} b \hat{y}_{t-1}\left((1-\theta) \frac{1}{\frac{1-\theta \frac{1}{\mu}}{1-\theta}-b}+\theta \frac{1}{\left(\frac{1}{\mu}\right)-b}\right) .
$$

\footnotetext{
${ }^{6}$ Just like Bilbiie we find that in principle a strong antinflation response can ensure determinacy under a Taylor rule for any value of $\theta$, but this would require implausibly large values for $\phi_{\pi}$. For instance, in our case $\theta^{*}=0.54$ if we set $\phi_{\pi}=40$ and $\theta^{*}=0.72$ if we set $\phi_{\pi}=100$.

${ }^{7}$ Given (14) and (19), steady state RT households marginal utility from consumption is positive only if $\left(\frac{1}{\mu}-b\right)>$ 0 . Our calibration for $b$ ensures that this condition holds.

${ }^{8}$ To preserve comparison with (32) we define profits as a fraction of steady state output.
} 
where $\chi^{*}=\frac{1-\phi_{l}\left(\frac{\mu}{1-\theta}-1\right)-\left(\frac{\theta}{1-\theta}\right) \frac{1}{\frac{1}{\mu}-b}}{1+\frac{1-\theta}{1-\frac{b(1-\theta)}{1-\theta \frac{1}{\mu}}} \frac{\mu-(1-\theta)}{\mu-\theta}-\frac{\theta}{\mu} \frac{1}{\frac{1}{\mu}-b}} \cdot{ }^{9}$ We also obtain

$$
\hat{c}_{t}^{r t}=\hat{w}_{t}+\hat{h}_{t}=\left(\begin{array}{c}
\hat{h}_{t} \frac{1+\frac{1-\theta}{1-\frac{b(1-\theta)}{1-\theta \frac{1}{\mu}}} \frac{\mu}{\mu-\theta}+\phi_{l}}{\left(1+\frac{1-\theta}{1-\frac{b(1-\theta)}{1-\theta \frac{1}{\mu}}} \frac{\mu-(1-\theta)}{\mu-\theta}-\frac{\theta}{\mu} \frac{1}{\frac{1}{\mu}-b}\right)}+ \\
-b \hat{c}_{t-1} \frac{\left((1-\theta) \frac{1}{\frac{1-\theta \frac{1}{\mu}}{1-\theta}-b}+\theta \frac{1}{\frac{1}{\mu}-b}\right)}{\left(1+\frac{(1-\theta)}{1-\frac{(1-\theta) b}{1-\theta \frac{1}{\mu}}} \frac{\mu-(1-\theta)}{\mu-\theta}-\frac{\theta}{\mu}\left(\frac{1}{\frac{1}{\mu}-b}\right)\right)}
\end{array}\right)
$$

Assuming a price markup $\mu=1.2$, we obtain $\chi^{*}<0$ if $0.042<\theta<0.46$, yet our calculations show that determinacy obtains only if $\theta$ does not exceed the threshold value $\theta^{* *} \simeq 0.13$. To understand this result consider that $\chi^{*}>0$ when $\theta>0.46$ because in this case the following condition holds

$$
\frac{\theta}{\mu} \frac{1}{\frac{1}{\mu}-b}>1+\frac{1-\theta}{1-\frac{b(1-\theta)}{1-\theta \frac{1}{\mu}}} \frac{\mu-1-\theta}{\mu-\theta},
$$

where term $\frac{1}{\frac{1}{\mu}-b} \frac{\theta}{\mu}$ defines $\theta \frac{\partial \hat{\lambda}_{t}^{r t}}{\partial \hat{w}_{t}}$. Note that (37) is also crucial to identify the sensitivity of $\hat{w}_{t}$ to $\hat{y}_{t}$.

$$
\begin{gathered}
\hat{w}_{t}=\phi_{l} \hat{h}_{t}+(1-\theta) \frac{\left(\frac{c^{o}}{c}\right) \hat{c}_{t}^{o}}{\left(\frac{c^{o}}{c}\right)-b}+\theta \frac{\left[\left(\frac{c^{r t}}{c}\right)\left(\hat{w}_{t}+\hat{h}_{t}\right)\right]}{\left(\frac{c^{r t}}{c}\right)-b}-b \hat{c}_{t-1} \frac{(1-\theta) \frac{c^{r t}}{c}+\theta \frac{c^{o}}{c}-b}{\left(\frac{c^{o}}{c}-b\right)\left(\frac{c^{r t}}{c}-b\right)}= \\
=\hat{y}_{t} \frac{\left(\phi_{l}+\frac{1-\theta}{1-\frac{(1-\theta)}{1-\frac{\theta}{\mu}} b} \frac{1-\theta}{\mu-\theta}+\frac{\frac{\theta}{\mu}}{\frac{1}{\mu}-b}\right)}{\left(1+\frac{1-\theta}{1-\frac{b(1-\theta)}{1-\frac{\theta}{\mu}}} \frac{\mu-(1-\theta)}{\mu-\theta}-\frac{\frac{\theta}{\mu}}{\frac{1}{\mu}-b}\right)}-b \hat{y}_{t-1} \frac{(1-\theta) \frac{c^{r t}}{c}+\theta \frac{c^{o}}{c}-b}{\left(\frac{c^{o}}{c}-b\right)\left(\frac{c^{r t}}{c}-b\right)}
\end{gathered}
$$

In fact when (37) holds, the effect of a wage change on the consumption marginal utility of RT households is so powerful that a positive wage reaction to an increase in labor demand cannot satisfy equation (21), and the sign of the wage reaction to the output gap is reversed. In this case an increase in output is associated to a fall in the real wage, to an increase in the consumption of optimizing households and to a fall in $\hat{c}_{t}^{r t}$, as documented in (36).

Finally, our calculations show that steady-state consumption inequality, measured by $\frac{c^{r t}}{c}=\frac{1}{\mu}$, expands the indeterminacy region: $\theta_{\mu=1.2, \rho=0}^{* *}<\theta_{\mu=1.2, \rho=\rho^{*}}^{* *}$ for $0.2 \leq \phi_{l} \leq 5$ (Figure 1). ${ }^{10}$

\footnotetext{
${ }^{9}$ Obviously if $\mu=1$ then $\chi^{*}=\chi$. Our calibration for $\mu$ ensures that $\left(\frac{1}{\mu}\right)-b>0$, i.e. the marginal utility of Rt consumption is positive in steady state.

${ }^{10}$ Our calculations also show that $\theta_{\mu=1.2, \rho=0}^{* *}<\theta_{\mu=1.2, \rho=\rho^{*}}^{* *}$ for any level of habit persistence such that $\left(\frac{1}{\mu}\right)-b>0$.
} 


\subsection{Model extensions}

\subsubsection{Sticky wages}

Previous contributions (Colciago, 2011; Ascari et al., 2011) suggest that under wage stickiness the potential indeterminacy caused by RT households is de facto unlikely. ${ }^{11}$ Following Colciago (2011), we model wage stickiness by assuming that in each period a fraction $\lambda_{w}$ of unions cannot reoptimize and hold their wage constant, whereas the remaining $\left(1-\lambda_{w}\right)$ unions set $\widetilde{W}_{t}$ to maximise a weighted average of the two household types utility functions, conditional to the probability that the wage cannot be reoptimized in the future.

$$
L^{u}=E_{t} \sum_{s=0}^{\infty}\left(\beta \lambda_{w}\right)^{s}\left\{\left[(1-\theta) U^{o}\left(c_{t+s}^{o}\right)+\theta U^{r t}\left(c_{t+s}^{r t}\right)\right]-U\left(h_{t+s}\right)\right\}
$$

The relevant constraints are (7), (10), and (11). Equation (13) is now replaced by

$$
\left\{E_{t} \sum_{s=0}^{\infty}\left(\beta \lambda_{w}\right)^{s}\left[(1-\theta) \lambda_{t+s}^{o}+\theta \lambda_{t+s}^{r t}\right] h_{t+s}^{d}\left(w_{t+s}\right)^{\alpha_{w}}\left[\widetilde{w}_{t}-\mu^{w} \frac{\psi_{l} h_{t+s}^{\phi_{l}}}{\left[(1-\theta) \lambda_{t+s}^{o}+\theta \lambda_{t+s}^{r t}\right]}\right]=0\right\}
$$

In loglinear form $(41)$ is

$$
\left[\begin{array}{c}
\left(\frac{1+\beta \lambda_{w}^{2}}{\left(1-\lambda_{w}\right)\left(1-\beta \lambda_{w}\right)}\right) \hat{w}_{t}-\beta \frac{\lambda_{w}}{\left(1-\lambda_{w}\right)\left(1-\beta \lambda_{w}\right)} \hat{w}_{t+1}+ \\
-\beta\left(\frac{\lambda_{w}}{\left(1-\lambda_{w}\right)\left(1-\beta \lambda_{w}\right)}\right) \hat{\pi}_{t+1}+\left(\frac{\lambda_{w}}{\left(1-\lambda_{w}\right)\left(1-\beta \lambda_{w}\right)}\right) \hat{\pi}_{t}+ \\
-\frac{\lambda_{w}}{\left(1-\lambda_{w}\right)\left(1-\beta \lambda_{w}\right)} \hat{w}_{t-1}
\end{array}\right]=\left\{\begin{array}{c}
\varphi \hat{h}_{t}-b \hat{c}_{t-1}\left[\frac{(1-\theta) \frac{c^{r t}}{c}+\theta\left(\frac{c^{o}}{c}\right)-b}{\left(\frac{c^{o}}{c}-b\right)\left(\frac{c^{r t}}{c}-b\right)}\right]+ \\
+(1-\theta) \frac{\left(\frac{c^{o}}{c}\right) \hat{c}_{t}^{o}}{\left(\frac{c^{o}}{c}\right)-b}+\theta \frac{\left[\left(\frac{c^{r t}}{c}\right)\left(\hat{w}_{t}+\hat{h}_{t}\right)\right]}{\left(\frac{c^{r t}}{c}\right)-b}
\end{array}\right\}
$$

Relative to (38), it is easy to see that nominal stickiness $\left(\lambda_{w}>0\right)$ dampens wage sensitivity to business cycle conditions and limits income redistribution between the two households groups when shocks hit the economy. As a result, the determinacy threshold is $\theta^{* *} \simeq 0.79$ if we set $\lambda_{w}=0.64 .^{12}$

\subsubsection{Capital accumulation}

We now extend our model to include those elements which are common in medium scale DSGE models (e.g. Christiano et al, 2005; Schmitt-Grohe and Uribe 2005) such as capital accumulation,variable capacity utilization and investment adjustment costs. Capital accumulation increases income and consumption inequality because under LAMP only Ricardian agents hold physical capital $\bar{k}$. Equations (2), (4), and (15) respectively become:

$$
\begin{gathered}
y_{t}(z)=\left(k_{t}(z)\right)^{\alpha}\left(h_{t}(z)\right)^{1-\alpha} \\
m c_{t}=\left[\left(\frac{r_{t}^{k}}{\alpha}\right)^{\alpha}\left(\frac{w_{t}}{(1-\alpha)}\right)^{1-\alpha}\right] \\
y_{t}=\left(k_{t}\right)^{\alpha}\left(h_{t}\right)^{1-\alpha}=c_{t}+i_{t}
\end{gathered}
$$

\footnotetext{
${ }^{11}$ We set $\lambda_{w}=0.64$ as in Christiano et al. (2005)

${ }^{12}$ This value is taken from Christiano et al (2005), and implies an average contract duration of 2.8 quarters.
} 
where $r_{t}^{k}$ is the net real rental rate of capital, $i_{t}$ defines real investment. ${ }^{13}$ Physical capital accumulation is driven by

$$
\bar{k}_{t+1}=(1-\vartheta) \bar{k}_{t}+i_{t}\left[1-S\left(\frac{i_{t}}{i_{t-1}}\right)\right]
$$

where

$$
k_{t}=u_{t} \bar{k}_{t}
$$

and $\vartheta$ and $S$ respectively denote the physical rate of depreciation and investment adjustment costs.

The following first order conditions describe demand functions for capital and investment and the optimal degree of capital utilization. ${ }^{14}$

$$
P_{k^{\prime}, t}=\beta E_{t}\left\{\lambda_{t+1}^{o} \frac{r_{t+1}^{k} u_{t+1}-a\left(u_{t+1}\right)+(1-\vartheta) P_{k^{\prime}, t+1}}{\lambda_{t}^{o}}\right\}
$$

The first order condition for investment is

$$
\lambda_{t}^{o}=E_{t}\left\{\begin{array}{c}
\lambda_{t}^{o} P_{k^{\prime}, t}\left[1-S\left(\frac{i_{t}}{i_{t-1}}\right)-S^{\prime}\left(\frac{i_{t}}{i_{t-1}}\right) \frac{i_{t}}{i_{t-1}}\right]+ \\
+\beta \lambda_{t+1}^{o} P_{k^{\prime}, t+1}\left[S^{\prime}\left(\frac{i_{t+1}}{i_{t}}\right)\left(\frac{i_{t+1}}{i_{t}}\right)^{2}\right]
\end{array}\right\}
$$

Following Christiano et al (2005) the investment adjustment cost function and the capital utilization function ${ }^{15}$ are:

$$
\begin{gathered}
S\left(\frac{i_{t}}{i_{t-1}}\right)=\frac{\omega}{2}\left(\frac{i_{t}}{i_{t-1}}-1\right)^{2} \\
a\left(u_{t}\right)=\gamma_{1}\left(u_{t}-1\right)+\frac{\gamma_{2}}{2}\left(u_{t}-1\right)^{2}
\end{gathered}
$$

where $P_{k^{\prime}, t}$ is the shadow relative price of one unit of capital with respect to one unit of consumption.

Capital holdings in the hands of Ricardian consumers unambiguously increase consumption inequality in steady state:

$$
\begin{aligned}
& \frac{c^{o}}{c^{r t}}=1+\frac{1}{1-\theta}\left\{\frac{\mu-1}{\mu}\left[\frac{1-\beta(1-\vartheta)}{\beta \alpha}\right]^{\frac{\alpha}{1-\alpha}}+\frac{(1-\beta) \alpha}{\beta(1-\beta(1-\vartheta))}\right\}\left(\frac{1}{\mu}\right)^{\frac{-1}{1-\alpha}} \frac{1}{1-\alpha} ; \\
& \frac{c^{r t}}{c}=\frac{1}{1+\left\{\frac{\mu-1}{\mu}\left[\frac{1-\beta(1-\vartheta)}{\beta \alpha}\right]^{\frac{\alpha}{1-\alpha}}+\frac{(1-\beta) \alpha}{\beta[1-\beta(1-\vartheta)]}\right\}\left(\frac{1}{\mu}\right)^{\frac{-1}{1-\alpha}} \frac{1}{1-\alpha}}
\end{aligned}
$$

Given the previous discussion about the complementarity between external habits and income inequality, we expect that the determinacy threshold should fall relative to the value $\theta^{* *} \simeq 0.79$ we obtained in section 3.2.1. We set $\alpha=0.36, \vartheta=0.025$,as in Christiano et al. (2005). This, in turn

\footnotetext{
${ }^{13}$ In the following we assume that $\rho=0$. See the appendix for a description of the full model

${ }^{14} P_{k^{\prime}, t}$ is the shadow relative price of one unit of capital with respect to one unit of consumption.

${ }^{15}$ Note that $S(1)=S^{\prime}(1)=0$ and $S^{\prime \prime}(1)>0$, implying the absence of adjustment costs up to a first order approximation of the deterministic steady state. The function $a(\cdot)$, instead, is assumed to satisfy $a(1)=0$ and $a^{\prime}(1), a^{\prime \prime}(1)>0$. Moreover the parameters $\gamma_{1}$ and $\gamma_{2}$ are fixed given that $a^{\prime}(u)=r^{k}$ at steady state.
} 
yields $\frac{c^{r t}}{c}=0.6936 .{ }^{16}$ Under this calibration we obtain $\theta^{* *} \simeq 0.29$. Thus consumption inequality in steady state has a very strong effect on the determinacy threshold. This happens because the larger consumption inequality, the more sensitive the nominal wage to the output gap, and the less effective is nominal wage stickiness in preserving determinacy.

\subsubsection{Sensitivity analysis}

Our analysis suggests that in a medium scale model determinacy should depend on a limited number of parameters. Among these, the capital income share $\alpha$ and the price markup $\mu$ influence steady state consumption inequality ${ }^{17}$, whereas the habit coefficient $b$, the inverse of the Frisch elasticity $\phi_{l}$, the parameters governing price and nominal wage stickiness, $\lambda_{p}$ and $\lambda_{w}$, affect income redistribution outside steady state.

Imposing $\mu=1$ is equivalent to assuming an efficient steady state. In this case $\theta^{* *}$ grows from 0.29 to 0.79 . Setting $\alpha=[0.3,0.4], \theta^{* *}$ varies between 0.45 and 0.11 .For values of $b$ in the range $[0.60,0.67], \theta^{* *}$ varies between 0.55 and $0.12 .{ }^{18}$ The threshold value $\theta^{* *}$ lies in the interval $[0.15,0.38]$ for values of $\phi_{l}$ in the range $[0.2,5]$. Wage stickiness is another key parameter: raising the frequency of wage adjustment to 4 quarters $\left(\lambda_{w}=0.8\right)$ the threshold value $\theta^{* *}$ reaches 0.42 . The opposite result obtains considering the same frequency of price stickiness $\left(\lambda_{p}=0.8\right)$ : in this case determinacy arises for $\theta^{* *}=0.23$. Prices and wages indexations do not play a significant role in determining the threshold quantity of RT consumers $\left(\theta^{* *}\right)$ for model determinacy.

\subsubsection{Fiscal redistribution}

Governments do reduce the dispersion of individual income and consumption levels by means of factor incomes taxation and redistributive transfers. ${ }^{19}$ To assess the potential effects of such policies in our framework we now introduce a constant fiscal transfer to RT consumers, financed by a lump-sum tax paid by Ricardian agents, as in Galì et al. (2007). By assumption, the transfer is proportional to the steady state consumption gap between the two households types.

$$
T=\gamma^{T}\left(c^{o}-c^{r t}\right)
$$

From our discussion reducing consumption inequality between the two groups is crucial to limit wage sensitivity to the output gap, the key factor that causes indeterminacy in our model. In Table 2 we show that for $\theta=0.3$ the ratio $\frac{c^{o}}{c^{r t}}$ falls from 1.65 to 1.19 as $\gamma^{T}$ is raised from 0 to 0.5 . Correspondingly, we observe important effects on the determinacy threshold $\theta^{* *}$, which grows from 0.29 to 0.71 .

\section{The redistributive effects of a monetary shock}

In this section ${ }^{20}$ we investigate the effects of an interest rate shock on aggregate volatility and on income and consumption inequality. In Table 3 we report standard deviations for key macroeco-

\footnotetext{
${ }^{16}$ Note that term $\frac{c^{r t}}{c}$ is independent from the fraction of RT consumers.

${ }^{17}$ See equation. $(51)$

${ }^{18} b=0.68$ is the maximum value we can set for the habit persistence in order to avoid a negative steady state marginal utility of consumption for RT consumers.

${ }^{19}$ See for instance Heathcote et al. (2010) for a discussion of the US case.

${ }^{20}$ In Appendix E we present the full model in log-linear form and provide details of shocks calibration.
} 
nomic variables under full asset market participation (column 1) and under LAMP $(\theta=0.25)$ for a different strength of the fiscal redistributive policy. In columns 2 and 3 we posit that $\theta=0.25^{21}$ whereas parameter $\gamma^{T}$ in (52) takes values 0 and 0.15 which implies a $20 \%$ reduction in the post tax Gini index in steady state. ${ }^{22}$ Then in column 4 we also consider the possibility that the fiscal transfer also reacts to cyclical consumption inequality

$$
\hat{T}=\tau\left(\hat{c}_{t}^{o}-\hat{c}_{t}^{r t}\right)
$$

where we set $\tau=0.5$ in line with a number of studies on the role of automatic stabilizers (Van den Noord, 2000; Westaway, 2003; Colciago et al. 2008; Motta and Tirelli, 2012).

It is easy to see that without fiscal policies LAMP causes a substantial increase in volatility, whereas redistributive fiscal policies have a powerful dampening effect on volatility. Indeed volatility figures obtained in the model characterized by LAMP-cum- fiscal-redistribution are very close to those obtained in the standard representative agent model. In addition, the bulk of the stabilization is obtained implementing steady state redistributive policies, whereas the cyclical rule (53) plays a lesser role. ${ }^{23}$

To support intuition, we plot IRFs to an interest rate shock. In Figure 2 we consider aggregate variables. Under full asset market participation inflation output, consumption, worked hours and the real wage fall. Introducing LAMP without fiscal policies causes an inversion in the relationship between the real interest rate and output, that now increases in response to the contraction. The real wage fall redistributes income in favor of Ricardian agents whose consumption grows, driving the surge in total consumption. The increase in hours raises the productivity of capital, inducing Ricardian households to raise investment as well. It is interesting to note that under full asset market participation Ricardian households would do just the opposite, decumulating capital to smooth consumption. Fiscal policies bring IRFs for aggregate variables under LAMP much closer to what we observe under full asset market participation. Nevertheless, the monetary policy shock still has redistributive effects between the two household groups. In fact, in spite of the fiscal policy actions the interest rate shock raises gapes in relative income and consumption levels $\left(\hat{y}_{t}^{o}-\hat{y}_{t}^{r t}\right.$, $\left.\hat{c}_{t}^{o}-\hat{c}_{t}^{r t}\right)$.

\section{Conclusion}

We embodied limited asset market participation in a popular medium scale New Keynesian DSGE model. We showed that external habits and consumption inequality have mutually reinforcing adverse effects on determinacy, uncovering a causality link between limited asset market participation, consumption inequality and macroeconomic volatility. Our framework also allows to investigate the redistributive effects of monetary policies which are associated to inequality of wealth holdings when risk sharing is precluded.

We have also shown that redistributive policies targeting consumption inequality have beneficial implications for macroeconomic stability, bringing the dynamic performance of the model close to the one generated by representative agent DSGE models. This suggests an intriguing conjecture: these latter models might apparently succeed in matching business cycle facts when in the

\footnotetext{
${ }^{21}$ This value appears consistent wth existing estimates for $\theta$ (Campbell and Mankiw, 1989; Coenen and Straub, 2005; Forni, Monteforte, and Sessa, 2009).

${ }^{22}$ This is consistent with empirical evidence for the US (Heathcote et al., 2010).

${ }^{23}$ Note that $\tau=0.5$ has a very modest positive effect on the determinacy threshold $\theta^{* *}$.
} 
real economy the underlying fiscal policy regime compensates for the effects of LAMP, but their performance might not be robust to fiscal reforms that limit discretionary policies and/or reduce the effectiveness of automatic fiscal stabilizers. Further, tighter regulation of financial markets in the aftermath of the 2007 financial crisis should be complemented with more interventionist fiscal policies. We leave this for future research. 


\section{References}

[1] Abel, A. 1990 Asset Prices under Habit Formation and Catching up with the Joneses The American Economic Review Vol. 80, No. 2, Papers and Proceedings of the Hundred and Second Annual Meeting of the American Economic Association (May, 1990), pp. 38-42

[2] Anderson, Emily and Inoue, Atsushi and Rossi, Barbara, Heterogeneous Consumers and Fiscal Policy Shocks (September 2013). CEPR Discussion Paper No. DP9631. Available at SSRN: http://ssrn.com/abstract $=2322726$

[3] Ascari Guido, Andrea Colciago and Lorenza Rossi, 2011 "Limited Asset Market Participation: Does it Really Matter for Monetary Policy" Bank of Finland Research Discussion Papers 15 2011.

[4] Bilbiie, Florin O., 2008. "Limited asset markets participation, monetary policy and (inverted) aggregate demand logic," Journal of Economic Theory, Elsevier, vol. 140(1), pages 162-196, May.

[5] Brave, Scott A., Campbell, Jeffrey R., Fisher, Jonas D. M. and Justiniano, Alejandro, The Chicago Fed DSGE Model (August 16, 2012). FRB of Chicago Working Paper No. 2012-02.

[6] Campbell, John Y. and Gregory N. Mankiw, 1989. "Consumption, Income, and Interest Rates: Reinterpreting the Time-Series Evidence," NBER Macroeconomics Annual.

[7] Christiano, Lawrence J, Martin Eichenbaum, and Charles L. Evans, 2005. "Nominal Rigidities and the Dynamic Effects of a Shock to Monetary Policy," Journal of Political Economy, University of Chicago Press, vol. 113(1), pages 1-45, February.

[8] Lawrence Christiano, Lawrence J, Roberto Motto, and Massimo Rostagno, 2010. Financial factors in economic fluctuations" Working Paper Series 1192, European Central Bank.

[9] Christoffel, K., Günter Coenen and Anders Warne, 2008. "The new area-wide model of the euro area - a micro-founded open-economy model for forecasting and policy analysis," Working Paper Series 944, European Central Bank. wealth: a cross-country analysis. AIAS, GINI Discussion Paper 71.

[10] Coenen, Günter and Roland Straub, 2005. "Does Government Spending Crowd in Private Consumption? Theory and Empirical Evidence for the Euro Area," International Finance, Blackwell Publishing, vol. 8(3), pages 435-470, December.

[11] Coenen, Günter, Roland Straub and Mathias Trabandt, 2012. "Fiscal Policy and the Great Recession in the Euro Area," American Economic Review, American Economic Association, vol. 102(3), pages 71-76, May.

[12] Coibion Olivier, Yuriy Gorodnichenko and Johannes Wieland, 2012. "The Optimal Inflation Rate in New Keynesian Models: Should Central Banks Raise Their Inflation Targets in Light of the Zero Lower Bound?," Review of Economic Studies, Oxford University Press, vol. 79(4), pages 1371-1406. 
[13] Colciago, A., Ropele, T., Muscatelli, V.A. and Tirelli, P., 2008. "The Role of Fiscal Policy in a Monetary Union: are National Automatic Stabilizers Effective?," Review of International Economics, Wiley Blackwell, vol. 16(3), pages 591-610, 08.

[14] Colciago, Andrea, 2011. "Rule of Thumb Consumers Meet Sticky Wages," Journal of Money, Credit and Banking

[15] Cowell F, Karagiannaki E, McKnight A, 2012. Mapping and measuring the distribution of household, LSE Research Online Documents on Economics 51288, London School of Economics and Political Science, LSE Library.

[16] Del Negro, M., Giannoni, M., Schorfheide, F. 2013 Inflation in the Great Recession and New Keynesian Models Federal Reserve Bank of New York Staff Reports, no. 618

[17] Felippa, Carlos. A. and K.C. Perk, 2004. "Synthesis Tools for Structural Dynamics and Partitioned Analysis of Coupled Systems," Aerospace Engineering Sciences and Center for Aerospace Structures.

[18] Forni, Lorenzo, Libero Monteforte and Luca Sessa, 2009. "The general equilibrium effects of fiscal policy: Estimates for the Euro area," Journal of Public Economics, Elsevier, vol. 93(3-4), pages 559-585, April.

[19] Furlanetto, F. and Seneca, M. (2012), Rule-of-Thumb Consumers, Productivity, and Hours. The Scandinavian Journal of Economics, 114: 658-679. doi: 10.1111/j.1467-9442.2012.01699.x

[20] Galí, Jordi, J. David López-Salido and Javier Vallés, 2004. "Rule-of-Thumb Consumers and the Design of Interest Rate Rules," NBER Working Papers 10392, National Bureau of Economic Research, Inc.

[21] Galí, Jordi, J. David López-Salido and Javier Vallés, 2007. "Understanding the Effects of Government Spending on Consumption," Journal of the European Economic Association, MIT Press, vol. 5(1), pages 227-270, 03.

[22] Heathcote, Jonathan \& Fabrizio Perri \& Giovanni L. Violante, 2010. "Unequal We Stand: An Empirical Analysis of Economic Inequality in the United States: 1967-2006," Review of Economic Dynamics, Elsevier for the Society for Economic Dynamics, vol. 13(1), pages 15-51, January.

[23] Iacoviello M. and Pavan M., 2013. "Housing and debt over the life cycle and over the business cycle," Journal of Monetary Economics, Elsevier, vol. 60(2), pages 221-238.

[24] Immervoll, Herwig and Linda Richardson, 2011. "Redistribution Policy and Inequality Reduction in OECD Countries: What Has Changed in Two Decades?," IZA Discussion Paper No. 6030

[25] Johnson, D. S., J. A. Parker, and N. S. Souleles, 2006. "Household Expenditure and the Income Tax Rebates of 2001", American Economic Review, 96, pp. 1589-1610.

[26] Mankiw, N. Gregory, 2000. "The Savers-Spenders Theory of Fiscal Policy," American Economic Review, American Economic Association, vol. 90(2), pages 120-125, May 
[27] Monacelli, T., Ahrend, R., \& Moeser, C. 2011. "How Institutions Shape the Distributive Impact of Macroeconomic Shocks: A DSGE Analysis," OECD Economics Department Working Papers 884, OECD Publishing.

[28] Motta, G., and Tirelli, P., 2012. "Optimal Simple Monetary and Fiscal Rules under Limited Asset Market Participation," Journal of Money, Credit and Banking, Blackwell Publishing, vol. 44(7), pages 1351-1374, October.

[29] Natvik, G. J. (2012), Government Spending Shocks and Rule-of-Thumb Consumers with Steady-State Inequality. The Scandinavian Journal of Economics, 114: 1414-1436. doi: 10.1111/j.1467-9442.2012.01727.x

[30] Oh, H., and R. Reis, 2011. "Targeted Transfers and the Fiscal Response to the Great Recession," NBER Working Papers 16775,

[31] Parker, J. A. N. S. Souleles, D. S. Johnson, and R. McClelland, 2011. "Consumer Spending and the Economic Stimulus Payments of 2008" NBER Working Paper No. 16684 January 2011.

[32] Rossi, Raffaele, 2011. "Designing Monetary and Fiscal Policy Rules in a New Keynesian Model with Rule-of-Thumb Consumers". Mimeo

[33] Samuelson, P., (1941) "Conditions That the Roots of a Polynomial be Less Than Unity in Absolute Value" The Annals of Mathematical Statistics, Vol. 12, No. 3, pp 360-364.

[34] Shapiro, M. W. and J. B. Slemrod, 2009. "Did the 2008 Tax Rebates Stimulate Spending?", American Economic Review, May, 99(2), pp. 374-79.

[35] Schmitt-Grohé, Stephanie and Martín Uribe, 2005. "Optimal Fiscal and Monetary Policy in a Medium-Scale Macroeconomic Model," NBER Chapters, in: NBER Macroeconomics Annual 2005, Volume 20, pages 383-462 National Bureau of Economic Research, Inc.

[36] Smets, Frank and Raf Wouters, 2003. "An Estimated Dynamic Stochastic General Equilibrium Model of the Euro Area," Journal of the European Economic Association, MIT Press, vol. 1(5), pages 1123-1175, 09.

[37] Smets, Frank and Raf Wouters, 2005. "Comparing shocks and frictions in US and euro area business cycles: a Bayesian DSGE Approach," Journal of Applied Econometrics, John Wiley \& Sons, Ltd., vol. 20(2), pages 161-183

[38] Smets, Frank and Raf Wouters, 2007. "Shocks and Frictions in US Business Cycles: A Bayesian DSGE Approach," American Economic Review, American Economic Association, vol. 97(3), pages 586-606, June.

[39] Van den Noord, P., 2000"The Size and Role of Automatic Fiscal Stabilizers in the 1990s and Beyond," OECD working paper ECO/WKP 2000 (3) .

[40] Westaway, P., "Modelling Shocks and Adjustment Mechanisms in EMU," EMU Studies, London: HM Treasury (2003). 


\section{Tables and Figures}

Table 1: Calibration

\begin{tabular}{|l|l|l|}
\hline \hline Parameter & Value & Description \\
\hline \hline$b$ & 0.65 & degree of habit persistence \\
\hline$\beta$ & $(1.03)^{-0.25}$ & subjective discount factor \\
\hline$\alpha$ & 0.36 & share of capital \\
\hline$\vartheta$ & 0.025 & depreciation rate \\
\hline$\eta$ & 6 & price-elasticity of demand for a differentiated good \\
\hline$\alpha_{w}$ & 21 & intratemporal elasticity of substitution between labor inputs \\
\hline$\kappa$ & 2.48 & parameter governing investment adjustment costs \\
\hline$\lambda_{w}$ & 0.64 & degree of wage stickiness \\
\hline$\lambda_{p}$ & 0.6 & degree of price stickiness \\
\hline$\psi_{l}$ & 1 & preference parameter \\
\hline$\phi_{l}$ & 3 & Inverse of Frish elasticity \\
\hline$\rho$ & 0 & production subsidy \\
\hline$\rho_{m}$ & 0.15 & autocorrelation of the monetary shock \\
\hline$\rho_{a}$ & 0.95 & autocorrelation of the technology shock \\
\hline$\sigma_{m}$ & 0.24 & standard deviation of the monetary shock \\
\hline$\sigma_{a}$ & 0.45 & standard deviation of the technology shock \\
\hline
\end{tabular}

Table 2: Fiscal transfer, redistribution and model stability

\begin{tabular}{|l|l|l|l|l|l|l|l|}
\hline \hline & $\gamma_{T}=0$ & $\gamma_{T}=0.05$ & $\gamma_{T}=0.1$ & $\gamma_{T}=0.15$ & $\gamma_{T}=0.2$ & $\gamma_{T}=0.25$ & $\gamma_{T}=0.5$ \\
\hline \hline$\theta^{* *}$ & 0.29 & 0.46 & 0.54 & 0.59 & 0.62 & 0.65 & 0.72 \\
\hline$\frac{c^{\circ}}{c^{r t}}$ when $\theta=0.3$ & 1.63 & 1.51 & 1.43 & 1.37 & 1.32 & 1.29 & 1.19 \\
\hline \hline
\end{tabular}

Values represent percentage standard deviations 
Table 3: Theoretical Moments

\begin{tabular}{|l||l|l|l|l||}
\hline \hline \multicolumn{1}{|c||}{ monetary shock $\left(\sigma_{r}=0.24, \rho_{r}=0.15\right)$} & \\
\hline \hline$x$ & $\theta=0$ no fiscal & $\theta=0.25$ no fiscal & $\theta=0.25, \gamma_{T}=0.15$ & $\theta=0.25, \gamma_{T}=0.15, \tau=0.5$ \\
\hline \hline$\hat{y}$ & 0.0398 & 0.1064 & 0.0375 & 0.0385 \\
\hline$\hat{c}$ & 0.0139 & 0.0706 & 0.0259 & 0.0190 \\
\hline$\pi$ & 0.0303 & 0.1493 & 0.0564 & 0.0449 \\
\hline$\hat{h}$ & 0.0460 & 0.1531 & 0.0391 & 0.0423 \\
\hline$\hat{w}$ & 0.0331 & 0.2172 & 0.0688 & 0.0530 \\
\hline$i$ & 0.1102 & 0.3659 & 0.0590 & 0.0719 \\
\hline$c^{o}$ & 0.0139 & 0.0825 & 0.0121 & 0.0106 \\
\hline$c^{r t}$ & - & 0.0909 & 0.0899 & 0.0560 \\
\hline$m c$ & 0.0376 & 0.1582 & 0.0684 & 0.0550 \\
\hline \hline
\end{tabular}

Values represent standard deviations

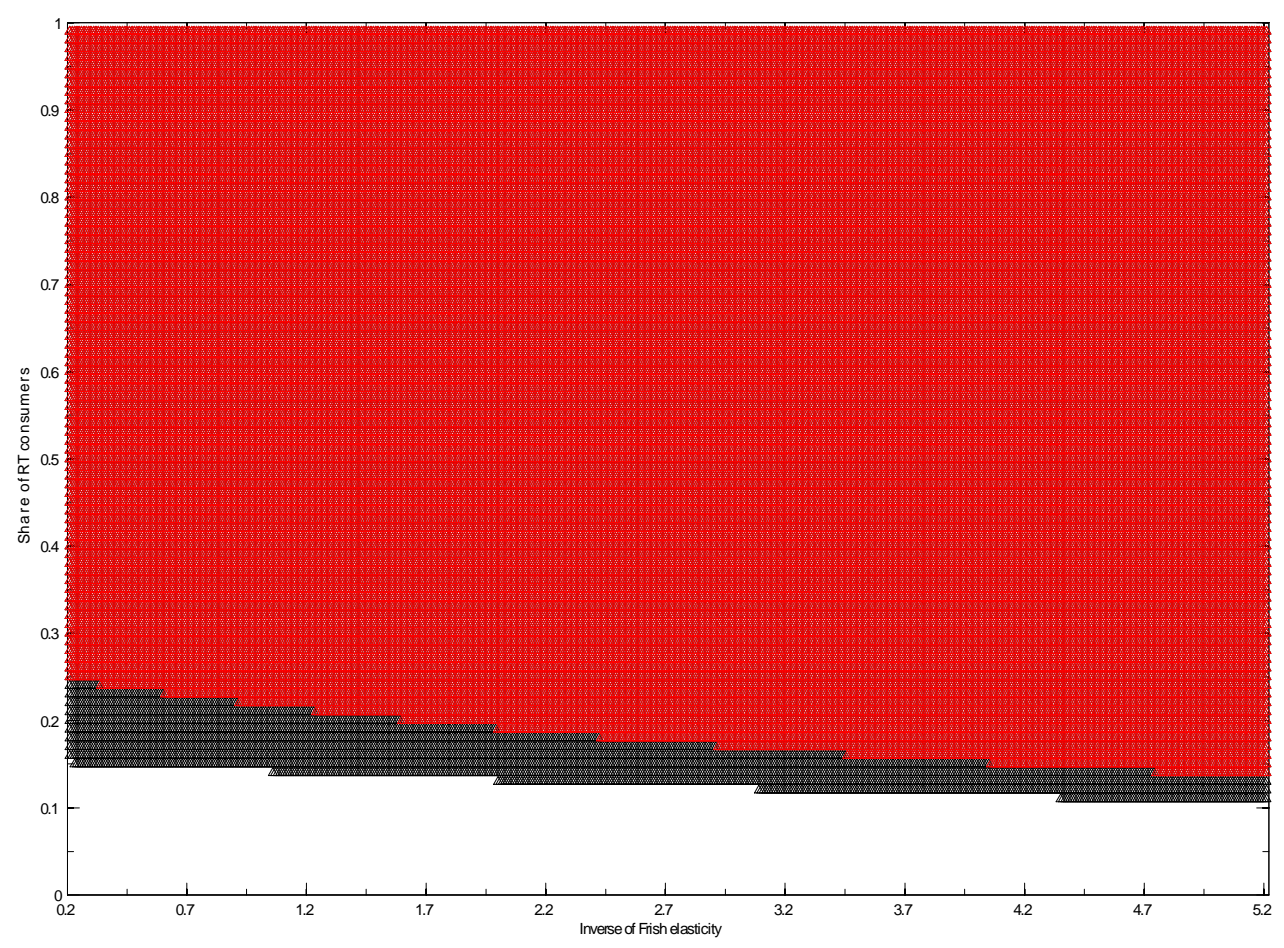

Figure 1: Red area represent the indeterminacy region when the steady state is efficient, i.e. $\rho=\rho^{*}$. The sum of red and black areas represents the indeterminacy region when the steady state is not efficient, i.e. $\rho=0$. 

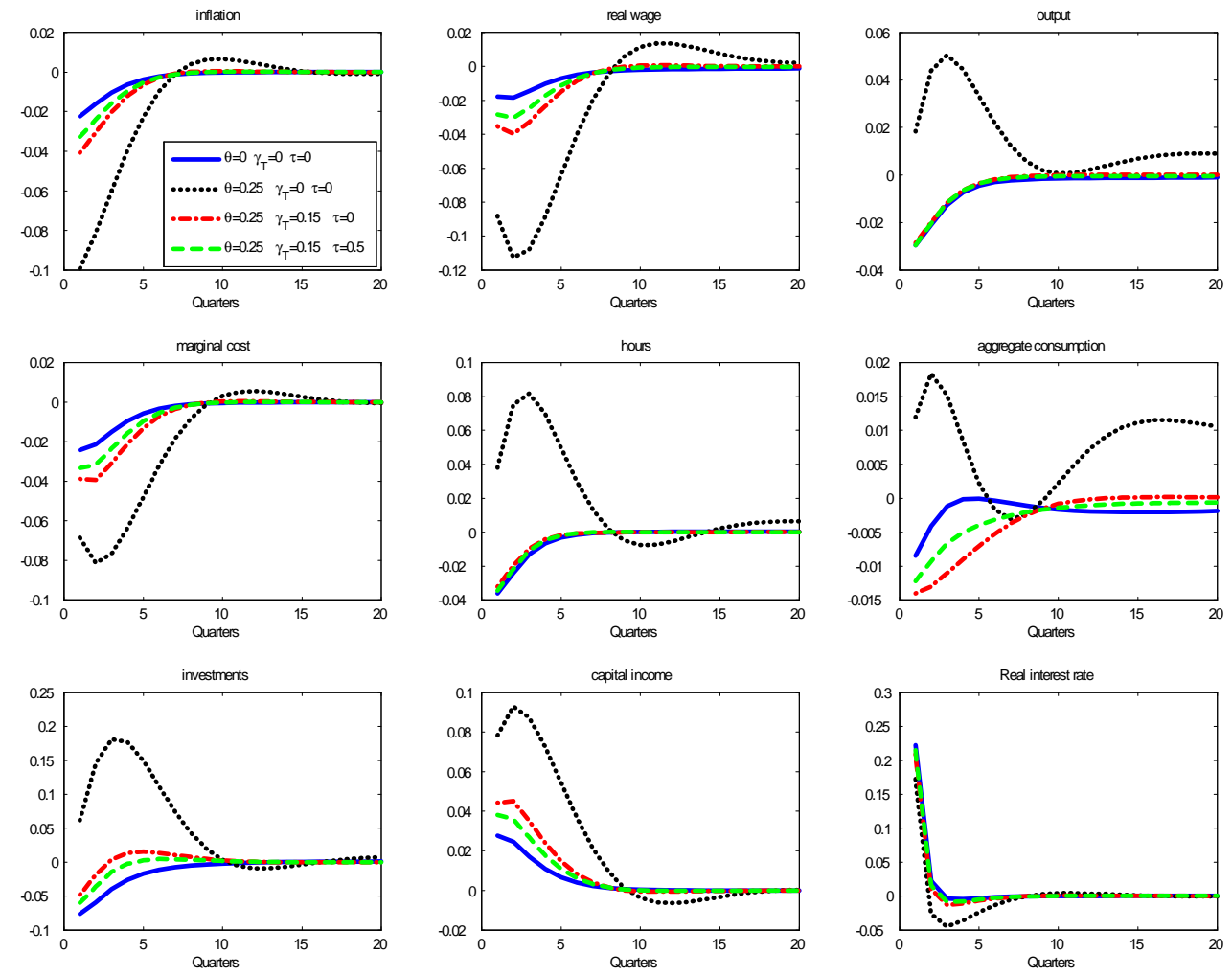

Figure 2: Impulse response functions to a restrictionary monetary policy shock 

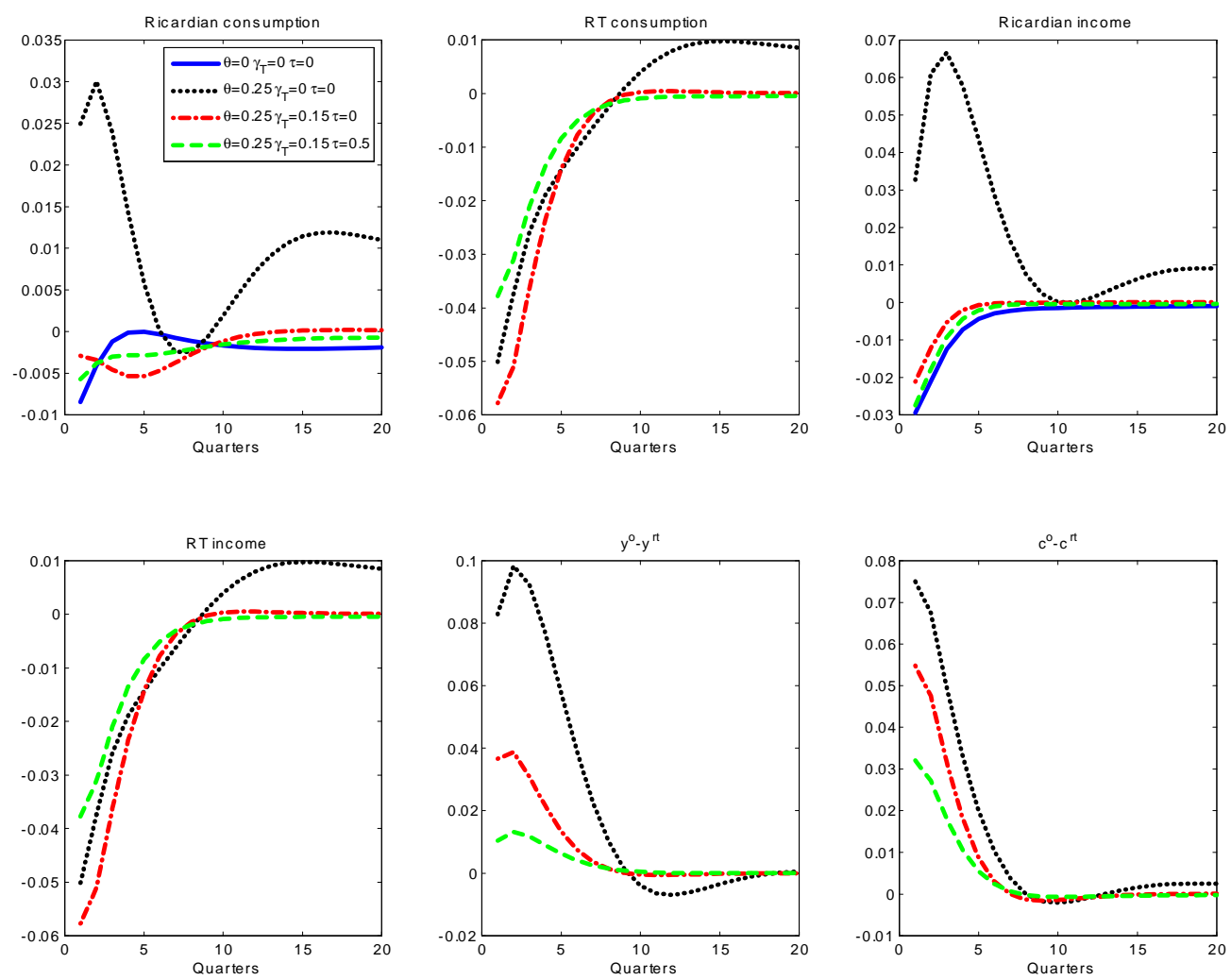

Figure 3: Impulse response functions to a restrictionary monetary policy shock 


\section{A Determinacy Analysis}

\section{A.1 Proof of Proposition 1:}

Consider the reduced form of the model

$$
\left(\begin{array}{c}
\hat{\pi}_{t+1} \\
\hat{y}_{t+1} \\
\hat{y}_{t}
\end{array}\right)=\left(\begin{array}{ccc}
\frac{1}{\beta} & -\frac{\kappa}{\beta}\left(\phi_{l}-\frac{1}{b-1}\right) & -b \frac{\kappa}{\beta(b-1)} \\
\frac{1}{B} \phi_{\pi}-\frac{1}{B \beta} & \frac{1}{B}(A+B)+\frac{1}{B} \frac{\kappa}{\beta}\left(\phi_{l}-\frac{1}{b-1}\right) & \frac{1}{B} b \frac{\kappa}{\beta(b-1)}-\frac{A}{B} \\
0 & 1 & 0
\end{array}\right)\left(\begin{array}{c}
\hat{\pi}_{t} \\
\hat{y}_{t} \\
\hat{y}_{t-1}
\end{array}\right),
$$

where

$$
\begin{aligned}
A & =\frac{b}{1-b}\left(1-\frac{1}{1-b} \frac{\theta}{1-\theta}\right) \\
B & =\frac{\left(1-\theta-\theta\left(\phi_{l}+\frac{1}{1-b}\right)\right)}{(1-b)(1-\theta)}, \\
k & =\frac{\left(1-\lambda_{p}\right)\left(1-\beta \lambda_{p}\right)}{\lambda_{p}} .
\end{aligned}
$$

The system is characterized by two jump variables $\left(\hat{\pi}_{t}\right.$ and $\left.\hat{y}_{t}\right)$ and one state variable $\left(\hat{y}_{t-1}\right)$. The Characteristic polynomial is

$$
\begin{aligned}
& P_{T}(X)=X^{3}+a_{2} X^{2}+a_{1} X+a_{0}= \\
= & X^{3}+\underbrace{\left(-\frac{1}{\beta}-\frac{(A+B)}{B}-\frac{\kappa}{B \beta}\left(\phi_{l}-\frac{1}{b-1}\right)\right)}_{a_{2}=- \text { Trace }} X^{2}+ \\
& +\underbrace{\left(\begin{array}{c}
\frac{1}{\beta}\left(\frac{(A+B)}{B}+\frac{\kappa}{B \beta}\left(\phi_{l}-\frac{1}{b-1}\right)\right)+\frac{A}{B}+ \\
-\frac{\kappa}{\beta}\left(\phi_{l}-\frac{1}{b-1}\right)\left(\frac{1}{B \beta}-\frac{\phi_{\pi}}{B}\right)-\frac{\kappa}{B \beta} \frac{b}{(b-1)}
\end{array}\right)}_{a_{1}=\text { Sum of leading minors }} X+ \\
& +\underbrace{\left(\frac{\left(A-A b+b \kappa \phi_{\pi}\right)}{B \beta(b-1)}\right)}_{a_{0}=- \text { Determinant }} .
\end{aligned}
$$

The stability properties of the system depend on the location of the roots inside the unit circle in the complex plane, i.e. $\left|X_{i}\right|<1$. By adopting the conformal involuntary transformation

$$
X=\left(\frac{1+x}{1-x}\right)
$$

it is in general possible to turn $P_{T}(X)$ into a Hurwitz polynomial ${ }^{24} P_{H}(x)$, whose stability properties depend on the location of the roots in the left hand plane $\mathcal{R}(X)<0:{ }^{25}$

$$
P_{H}(x)=\left(\frac{1+x}{1-x}\right)^{3}+a_{2}\left(\frac{1+x}{1-x}\right)^{2}+a_{1}\left(\frac{1+x}{1-x}\right)+a_{0}
$$

\footnotetext{
${ }^{24}$ Note that $|X| \gtrless 1 \Longleftrightarrow x \gtrless 0$

${ }^{25}$ See Samuelson (1941) and more recently, Felippa and Park (2004)- section 4 page 18, Ascari et al. (2011) and Rossi (2011).
} 
which can be rewritten as

$$
\begin{aligned}
P_{H}(X)= & x^{3}+\underbrace{\left(\frac{\left(3 a_{0}-a_{1}-a_{2}+3\right)}{\left(a_{1}-a_{0}-a_{2}+1\right)}\right)}_{d_{2}} x^{2}+ \\
& +\underbrace{\left(\frac{\left(a_{2}-a_{1}-3 a_{0}+3\right)}{\left(a_{1}-a_{0}-a_{2}+1\right)}\right)}_{d_{1}} x+ \\
& +\underbrace{\frac{\left(a_{0}+a_{1}+a_{2}+1\right)}{\left(a_{1}-a_{0}-a_{2}+1\right)}}_{d_{0}}=0
\end{aligned}
$$

Therefore:

$$
\begin{aligned}
d_{0} & =\frac{1+a_{2}+a_{1}+a_{0}}{1-a_{2}+a_{1}-a_{0}}=-x_{1} x_{2} x_{3} \\
d_{1} & =\frac{3+a_{2}-a_{1}-3 a_{0}}{1-a_{2}+a_{1}-a_{0}}=x_{1} x_{2}+x_{1} x_{3}+x_{2} x_{3} \\
d_{2} & =\frac{3-a_{2}-a_{1}+3 a_{0}}{1-a_{2}+a_{1}-a_{0}}=-\left(x_{1}+x_{2}+x_{3}\right)
\end{aligned}
$$

where $x_{i}, i=1,3$ are the roots of $P_{H}(x)$.

The necessary condition for model's stability is:

$$
d_{0}=\frac{\kappa\left(\phi_{l}+1\right)\left(\phi_{\pi}-1\right)}{\left(\kappa\left(\phi_{l}+\frac{1}{1-b}\right)+b \frac{\kappa}{1-b}\right)\left(\phi_{\pi}+1\right)+(2 \beta+2)(A+B)}>0
$$

Under the Taylor principle $\phi_{\pi}-1>0$, therefore

$$
d_{0}>0 \Leftrightarrow(A+B)>-\frac{\kappa\left(\left(\phi_{l}+\frac{1}{1-b}\right)+\frac{b}{1-b}\right)\left(\phi_{\pi}+1\right)}{2(\beta+1)}
$$

that is

$$
\theta<\frac{\left(1+b+\frac{(1-b) \kappa\left(\left(\phi_{l}+\frac{1}{1-b}\right)+\frac{b}{1-b}\right)\left(\phi_{\pi}+1\right)}{2(\beta+1)}\right)}{\frac{1+b}{1-b}+\phi_{l}+\left(1+b+\frac{(1-b) \kappa\left(\left(\phi_{l}+\frac{1}{1-b}\right)+\frac{b}{1-b}\right)\left(\phi_{\pi}+1\right)}{2(\beta+1)}\right)}
$$

When (54) holds, by Descartes rule stability obtains if either $d_{1}$ or $d_{2}$ or both are negative.

Since $d_{1}<0$ if

$$
\theta<\frac{\left(2(1-\beta)(1-b)+\kappa\left(1+b+\phi_{l}(1-b)\right)+\kappa \phi_{\pi}\left(\left(1+\phi_{l}\right)(1-b)-2 b\right)\right)}{\left(2(1-\beta)\left(\phi_{l}-b+2\right)+\kappa\left(1+b+\phi_{l}(1-b)\right)+\kappa \phi_{\pi}\left(\left(1+\phi_{l}\right)(1-b)-2 b\right)\right)}
$$

which is always true when condition (54) is satisfied, condition (54) is the necessary and sufficient condition for determinacy under the Taylor principle. 


\section{B Derivation of (35)}

The Ricardian consumption can be written as

$$
\begin{aligned}
\hat{c}_{t}^{o} & =\frac{w h}{c^{o}} \hat{w}_{t}+\frac{w h}{c^{o}} \hat{h}_{t}+\frac{h}{c^{o}} \frac{\hat{d}_{t}}{1-\theta}= \\
& =\frac{w h}{c^{o}} \hat{w}_{t}+\frac{w h}{c^{o}} \hat{h}_{t}-\frac{h w}{c^{o}} \frac{\hat{w}_{t}}{1-\theta}= \\
& =\frac{1}{1+\frac{\mu-1}{\mu}}\left(\hat{h}_{t}-\frac{\theta}{(1-\theta)} \hat{w}_{t}\right) .
\end{aligned}
$$

where the real wage is

$$
\hat{w}_{t}=\phi_{l} \hat{h}_{t}-\left[(1-\theta) \hat{\lambda}_{t}^{o}+\theta \hat{\lambda}_{t}^{r t}\right]
$$

and $\hat{\lambda}_{t}^{j}=-\frac{1}{\left(\frac{c^{j}}{c}\right)-b}\left[\left(\frac{c^{j}}{c}\right) \hat{c}_{t}^{j}-b \hat{c}_{t-1}\right]$ are the marginal utilities of consumption for the two types of households. Substitutig $\hat{\lambda}_{t}^{r t}$ into the wage equation we obtain

$$
\hat{w}_{t}=\phi_{l} \hat{h}_{t}-\left\{(1-\theta) \hat{\lambda}_{t}^{o}-\frac{\theta}{\frac{1}{\mu}-b}\left[\left(\frac{1}{\mu}\right) \hat{c}_{t}^{r t}-b \hat{c}_{t-1}\right]\right\}
$$

Remembering that $\hat{c}_{t}^{r t}=\hat{w}_{t}+\hat{h}_{t}$ we obtain

$$
\hat{w}_{t}=\phi_{l} \hat{h}_{t}-\left[(1-\theta) \hat{\lambda}_{t}^{o}-\frac{\theta}{\frac{1}{\mu}-b}\left[\left(\frac{1}{\mu}\right)\left(\hat{w}_{t}+\hat{h}_{t}\right)-b \hat{c}_{t-1}\right]\right]
$$

and after few manipulations

$$
\hat{w}_{t}=\left(\frac{\phi_{l}}{\left(1-\frac{\theta}{\frac{1}{\mu}-b}\left(\frac{1}{\mu}\right)\right)}\left(1+\frac{\theta}{\frac{1}{\mu}-b}\left(\frac{1}{\mu}\right)\right) \hat{h}_{t}+\left[(1-\theta) \frac{1}{\left(\frac{c^{o}}{c}\right)-b}\left[\left(\frac{c^{o}}{c}\right) \hat{c}_{t}^{o}\right]-\left((1-\theta) \frac{1}{\left(\frac{c^{o}}{c}\right)-b}+\frac{\theta}{\frac{1}{\mu}-b}\right) b \hat{c}_{t-1}\right]\right)
$$

Plugging it back into (56) and collecting $\hat{c}_{t}^{o}$ we get

$$
\hat{c}_{t}^{o}=\frac{\hat{h}_{t} \frac{1}{1+\frac{\mu-1}{\mu}}\left(1-\frac{\theta}{1-\theta} \frac{\phi_{l}\left(1+\frac{\theta}{\frac{1}{\mu}-b} \frac{1}{\mu}\right)}{\left(1-\frac{\theta}{\frac{1}{\mu}-b} \frac{1}{\mu}\right)}\right)+\frac{1}{1+\frac{\mu-1}{\mu}} \frac{\theta}{(1-\theta)}\left((1-\theta) \frac{1}{\left(\frac{c^{o}}{c}\right)-b}+\frac{\theta}{\frac{1}{\mu}-b}\right) b \hat{c}_{t-1}}{\left(1+\frac{1}{1+\frac{\mu-1}{\mu}} \theta \frac{\frac{c o}{c}}{\frac{c o}{c}-b}\right)}
$$

\section{Derivation of (38)}

We can rewrite the wage setting condition

$$
\hat{w}_{t}=\phi_{l} \hat{h}_{t}-\left[(1-\theta) \hat{\lambda}_{t}^{o}+\theta \hat{\lambda}_{t}^{r t}\right] .
$$


as

$$
\hat{w}_{t}=\phi_{l} \hat{h}_{t}+\frac{(1-\theta)}{\frac{c^{o}}{c}-b}\left[\left(\frac{c^{o}}{c}\right) \hat{c}_{t}^{j}-b \hat{c}_{t-1}\right]+\frac{\theta}{\left(\frac{c^{r t}}{c}\right)-b}\left[\left(\frac{c^{r t}}{c}\right) \hat{c}_{t}^{r t}-b \hat{c}_{t-1}\right] .
$$

or

$$
\hat{w}_{t}=\phi_{l} \hat{h}_{t}+\frac{(1-\theta)}{\frac{c^{o}}{c}-b}\left(\frac{c^{o}}{c}\right) \hat{c}_{t}^{o}+\frac{\theta}{\frac{c^{r t}}{c}-b}\left(\frac{c^{r t}}{c}\right) \hat{c}_{t}^{r t}-w^{b} b \hat{c}_{t-1} .
$$

where $w^{b}=\frac{(1-\theta)}{\frac{c^{\circ}}{c}-b}+\frac{\theta}{\frac{c^{r t}}{c}-b}$. Substituting for the definitions of RT and Ricardian consumptions and collecting for the wage we obtain

$$
\hat{w}_{t}=\frac{\left(\phi_{l}+\frac{\left(1-\theta \frac{1}{\mu}\right) \chi^{*}}{\left(\frac{c^{o}}{c}-b\right)\left(1+\frac{\mu-1}{\mu}\right)+\theta \frac{c^{o}}{c}}+\frac{\theta \frac{1}{\mu}}{\left(\frac{1}{\mu}\right)-b}\right)}{\left(1-\frac{\theta \frac{1}{\mu}}{\left(\frac{1}{\mu}\right)-b}\right)} \hat{y}_{t}-\frac{w^{b} b \hat{c}_{t-1}}{\left(1-\frac{\theta \frac{1}{\mu}}{\left(\frac{1}{\mu}\right)-b}\right)}
$$

where $\chi^{*}=1-\frac{\theta}{1-\theta} \Omega$, and $\Omega=\frac{\phi_{l}\left(1+\frac{1}{\frac{1}{\mu}-b} \frac{\theta}{\mu}\right)}{1-\frac{1}{\frac{1}{\mu}-b} \frac{\theta}{\mu}}$

\section{Steady state of the full model}

The presence of RT consumers influences the steady state uniquely for what concerns households individual consumption levels. From equations (8) and (48), and assuming zero inflation in steady state, it holds true that

$$
\begin{gathered}
R=\frac{1}{\beta} \\
r^{k}=\frac{1}{\beta}-1+\vartheta \\
m c=\left(\frac{\eta}{\eta-1}\right)^{-1}
\end{gathered}
$$

From the cost minimization problem we obtain:

$$
\begin{aligned}
\left(\frac{k}{h}\right) & =\left[\left(\frac{\eta}{\eta-1}\right)\left(\frac{1}{\beta}-1+\vartheta\right) \frac{1}{\alpha}\right]^{\frac{1}{\alpha-1}} \\
w & =\left(\frac{\eta}{\eta-1}\right)^{-1}(1-\alpha)\left(\frac{k}{h}\right)^{\alpha}
\end{aligned}
$$

From the production function we get

$$
\frac{y}{h}=\left(\frac{k}{h}\right)^{\alpha}
$$

Since

$$
\frac{i}{y}=\vartheta \frac{k}{y}
$$


the aggregate resource constraint reads as:

$$
\begin{gathered}
y=c+i \\
1=\frac{c}{y}+\frac{i}{y}
\end{gathered}
$$

The aggregate consumption-output ratio is

$$
\frac{c}{y}=1-\vartheta \frac{k}{h}\left(\frac{y}{h}\right)^{-1}
$$

The equation for the optimal wage allows us to derive the solution for worked hours

$$
h=\left[\frac{\alpha_{w}-1}{\alpha_{w}}\left(\frac{(1-\theta)}{\frac{c^{o}}{c}-b}+\frac{\theta}{\frac{c^{r t}}{c}-b}\right) \frac{c^{r t}}{c}\right]^{\frac{1}{\left(\phi_{l}+1\right)}}
$$

so that

$$
k=\frac{k}{h} h
$$

$\mathrm{RT}$ individual consumption is

$$
c^{r t}=w h
$$

therefore

$$
\frac{c^{r t}}{c}=\left(\frac{c}{y}\right)^{-1} w\left(\frac{y}{h}\right)^{-1}
$$

From the total consumption identity $c=(1-\theta) c^{o}+\theta c^{r t}$ we get

$$
\frac{c^{o}}{c}=\frac{1}{1-\theta}-\frac{\theta}{1-\theta} \frac{c^{r t}}{c}
$$

Optimizing households consumption at steady state is given by the sum of labour income, firms profits return of capital and returns of money rents to firms:

$$
c^{o}=w h+\frac{1}{1-\theta}\left(d+\left(r^{k}-\vartheta\right) K\right)
$$

where $d=(1-m c) y=\left(1-\frac{1}{\mu}\right) y$ and $\mu=\frac{\eta}{\eta-1}$ denotes firms markup. Thus optimizing agents are richer the higher the share of RT consumers. Aggregate consumption can be finally rewritten as

$$
c=(1-\theta) c^{o}+\theta c^{r t}=w h+\Pi+\left(r^{k}-\vartheta\right) K+v(R-1) w h
$$

\section{E The full model in log-linear form.}

Here we present the log-linearized model simulated in section 4 . Shocks are introduced as follows. Condition (43) now becomes

$$
y_{t}(z)=A_{t}\left(k_{t}(z)\right)^{\alpha}\left(h_{t}(z)\right)^{1-\alpha}
$$


where $A_{t}$ is an exogenous stochastic TFP term fluctuationg around a steady state value normalized at one,

$$
\hat{a}_{t}=\rho_{a} \hat{a}_{t-1}+\varepsilon_{t}^{a}, \varepsilon_{t}^{a} \sim N\left(0, \sigma_{a}^{2}\right) .
$$

The monetary policy shock enters (29) which becomes

$$
\begin{aligned}
& \hat{R}_{t}=\phi_{\pi} \hat{\pi}_{t}+\gamma_{t}, \\
& \gamma_{t}=\rho_{m} \gamma_{t-1}+\varepsilon_{t}^{m}, \varepsilon_{t}^{m} \sim N\left(0, \sigma_{m}^{2}\right) .
\end{aligned}
$$

Aggregate consumption is defined by:

$$
\hat{c}_{t}=(1-\theta) \frac{c^{o}}{c} \hat{c}_{t}^{o}+\theta \frac{c^{r t}}{c} \hat{w}_{t}+\theta \frac{c^{r t}}{c} \hat{h}_{t}
$$

Marginal costs are given by

$$
\widehat{m c}_{t}=(1-\alpha)\left(\hat{w}_{t}\right)+\alpha \hat{r}_{t}^{k}-\hat{a}_{t}
$$

The following equation combines firms' F.O.C. with respect to production factors

$$
\hat{h}_{t}+\hat{w}_{t}=\hat{k}_{t-1}+\left(1+\frac{\gamma_{1}}{\gamma_{2}}\right) \hat{r}_{t}^{k}
$$

Production function is given by

$$
\hat{y}_{t}=\alpha \hat{k}_{t-1}+\alpha \frac{\gamma_{1}}{\gamma_{2}} \hat{r}_{t}^{k}+(1-\alpha) \hat{h}_{t}+\hat{a}_{t}
$$

Aggregate resource constraint

$$
\hat{y}=\frac{i}{y} \hat{\imath}_{t}+\frac{c}{y} \hat{c}_{t}+\gamma_{1} \frac{\gamma_{1}}{\gamma_{2}} \frac{k}{y} \hat{r}_{t}^{k}
$$

RT consumption

$$
\hat{c}_{t}^{r t}=\hat{w}_{t}+\hat{h}_{t}
$$

Euler equation

$$
\hat{\lambda}_{t}^{o}=E_{t} \hat{\lambda}_{t+1}^{o}+E_{t}\left(\hat{R}_{t}-\hat{\pi}_{t+1}\right)
$$

Households marginal utility of consumption

$$
\begin{aligned}
& \hat{\lambda}_{t}^{o}=-\frac{1}{\left(\frac{c^{o}}{c}\right)-b}\left[\left(\frac{c^{o}}{c}\right) \hat{c}_{t}^{o}-b \hat{c}_{t-1}\right] \\
& \hat{\lambda}_{t}^{r t}=-\frac{1}{\left(\frac{c^{r t}}{c}\right)-b}\left[\left(\frac{c^{r t}}{c}\right) \hat{c}_{t}^{o}-b \hat{c}_{t-1}\right]
\end{aligned}
$$

Investment decisions

$$
\begin{gathered}
\hat{\imath}_{t}-\frac{1}{k(1+\beta)} \hat{P}_{k^{\prime}, t}-\frac{1}{(1+\beta)} \hat{\imath}_{t-1}-\frac{\beta}{(1+\beta)} E_{t} \hat{\imath}_{t+1}=0 \\
E_{t} \hat{\pi}_{t+1}+\beta(1-\vartheta) E_{t} \hat{P}_{k^{\prime}, t+1}-\hat{P}_{k^{\prime}, t}=E_{t} \hat{R}_{t+1}-\beta r^{k} E_{t} \hat{r}_{t+1}^{k}
\end{gathered}
$$




\section{Capital accumulation}

$$
\hat{k}_{t}=(1-\vartheta) \hat{k}_{t-1}+\vartheta \hat{\imath}_{t}
$$

Phillips Curve

$$
\frac{\lambda_{p}}{1-\lambda_{p}} \hat{\pi}_{t}=\left(1-\beta \lambda_{p}\right) \widehat{m c}_{t}+\beta \lambda_{p} \hat{\pi}_{t+1}+\beta \frac{\lambda_{p}^{2}}{1-\lambda_{p}} \hat{\pi}_{t+1}
$$

Wage dynamics

$$
\left[\begin{array}{c}
\left(\frac{1+\beta \lambda_{w}^{2}}{1-\lambda_{w}}\right) \hat{w}_{t}-\beta \frac{\lambda_{w}}{1-\lambda_{w}} \hat{w}_{t+1}+ \\
-\frac{\beta}{1-\lambda_{w}} \hat{\pi}_{t+1}+\frac{\lambda_{w}}{1-\lambda_{w}} \hat{\pi}_{t}+ \\
-\frac{\lambda_{w}}{1-\lambda_{w}} \hat{w}_{t-1}
\end{array}\right]=\left(1-\beta \lambda_{w}\right) \varphi \hat{h}_{t}-\left(1-\beta \lambda_{w}\right) \hat{\psi}_{t}
$$

where

$$
\hat{\psi}_{t}=\frac{(1-\theta)}{\frac{c^{r t}}{c}-b} \hat{\lambda}_{t}^{o}+\frac{\theta}{\frac{c^{r t}}{c}-b} \hat{\lambda}_{t}^{r t}
$$

